\title{
Kinetika Reaksi Pirolisis Enceng Gondok
}

\author{
Mitha Puspitasari $^{\mathrm{a}^{*}}$, Sutijan $^{\mathrm{b}}$, Arief Budiman ${ }^{\mathrm{b}}$ \\ ${ }^{\text {a} P r o g r a m ~ S t u d i ~ D 3 ~ T e k n i k ~ K i m i a, ~ J u r u s a n ~ T e k n i k ~ K i m i a, ~ F a k u l t a s ~ T e k n i k ~ K i m i a, ~}$ \\ Universitas Pembangunan Nasional "Veteran" Yogyakarta \\ Jl. SWK 104(Lingkar Utara), Condongcatur, Yogyakarta, 55283, Indonesia \\ bJurusan Teknik Kimia, Fakultas Teknik, Universitas Gadjah Mada Yogyakarta \\ JL. Grafika 2, Kampus UGM, Yogyakarta, 55281, Indonesia
}

\section{Artikel histori :}

Diterima 3 Februari 2016 Diterima dalam revisi 31 Maret 2016 Diterima 31 Maret 2016 Online Juni 2016

\begin{abstract}
ABSTRAK: Enceng gondok merupakan tanaman pengganggu dalam ekosistem air karena pertumbuhannya yang sangat cepat sehingga perlu dipikirkan cara untuk pemusnahan tanaman ini. Namun enceng gondok merupakan biomassa yang mempunyai kandungan hemiselulosa, selulosa dan lignin yang tinggi. Pirolisis adalah metode yang tepat untuk mengubah biomassa yang diproses secara termal menjadi produk yang bernilai. Pirolisis merupakan proses degradasi termal untuk mengahasilkan bio-char, bio-oil dan bio-gas tanpa adanya oksigen. Tujuan penelitian ini adalah untuk mencari suhu optimum dari proses pirolisis dan mencari parameter kinetika untuk membantu peneliti dalam merancang reaktor dan memahami reaksi yang terjadi. Model yang diusulkan untuk mempresentasikan reaksi pirolisis enceng gondok adalah Compatting model. Hasil dari penelitian ini menunjukkan bahwa suhu $600^{\circ} \mathrm{C}$ merupakan suhu optimum untuk mengahasilkan bio-oil. Dengan menggunakan program matlab konstanta kinetika reaksi pada pembentukan gas pada proses pirolisis enceng gondok adalah $\mathrm{k}_{1}=3,4997 \mathrm{exp}^{-14069,21 / \mathrm{RT}} \mathrm{men}^{-1}$, konstanta kinetika reaksi pembentukan bio-oil adalah $\mathrm{k}_{2}=0,3430 \exp ^{-3059,451 / R T}$ men $^{-1}$ dan konstanta kinetika reaksi pembentukan char adalah $\mathrm{k}_{3}=0,2526 \exp ^{-2313,395 / \mathrm{RT}} \mathrm{men}^{-1}$.
\end{abstract}

Kata Kunci: enceng gondok; pirolisis; kinetika

ABSTRACT: Water hyacinth is a weed plant that live in water with very high growth rates that should be considered a way for the destruction of this plant. However, the water hyacinth biomass has a high content of hemicellulose, cellulose and lignin. Pyrolysis is the method to convert biomass into valuable products by the thermal degradation process to produces a biochar, bio-oil and bio-gas. The purpose of this study was to find the optimum condition of the pyrolysis process and parameters of kinetics, to design the reactor and to understand the reactions that occur. The proposed model presented in the pyrolysis reaction of water hyacinth was Compatting models. The experiment showed that temperature of $600^{\circ} \mathrm{C}$ was the optimum temperature resulting the best bio-oil. Matlab program was used to determine the kinetic constant of reaction. The constant formation of gas in the pyrolysis process water hyacinth was $\mathrm{k}_{1}=3,4997 \mathrm{exp}^{-14069,21 / \mathrm{RT}} \mathrm{men}^{-1}$. The constant formation of bio-oil and char were $\mathrm{k}_{2}=0,3430 \mathrm{exp}^{-}$ $3059,451 / \mathrm{RT}$ men $^{-1}$ and $\mathrm{k}_{3}=0,2526 \mathrm{exp}^{-2313,395 / \mathrm{RT}}$ men $^{-1}$, respectively.

Keywords: water hyacinth, pyrolysis, kinetics

\section{Pendahuluan}

Enceng gondok (Eichhornia crassipes) merupakan tanaman gulma yang hidup terapung pada air dan berkembang biak dengan cepat baik secara vegetatif maupun generatif. Perkembangbiakan dengan cara vegetatif dapat melipat ganda dua kali dalam waktu 7-10 hari (Gunawan and Sahwalita, 2007). Soeb dan Sigh (2000) melaporkan bahwa kecepatan pertumbuhan enceng gondok adalah 17,5 ton/ha/hari, sehingga pemusnahan tumbuhan ini menjadi masalah besar. Padahal dengan proses termal tumbuhan ini dapat dihasilkan bio-oil.

\footnotetext{
*Corresponding Author:
}

Email: mitha.puspita1912@gmail.com
Menurut Huang dkk (2013), ada dua cara untuk mengkonversi biomassa menjadi bahan bakar atau kimia yaitu secara termo-kimia dan bio-kimia/biologi. Konversi biomassa secara termo-kimia dapat dilakukan dengan pirolisis, gasifikasi, pembakaran dan sebagainya. Pirolisis biomassa menurut Sharma dkk (2015) dikelompokan menjadi 2 kelompok utama yaitu fast pirolisis dan slow pirolisis. Fast pirolisis adalah pirolisis dengan pemanasan yang sangat tinggi dengan waktu tinggal gas yang singkat. Sedangkan slow pirolisis adalah pirolisis dengan pemanasan dan waktu tinggal uap yang lebih lama, 
biasanya suhunya lebih rendah dibanding dengan fast pirolisis.

Enceng gondok merupakan salah satu biomassa yang dapat dikonversi menjadi bio-oil melalui proses pirolisis. Hal ini diperkuat oleh Bhattacharya and Kumar (2010) yang mengemukakan bahwa enceng gondok merupakan tanaman bahan bakar bio yang sangat potensial dikembangkan. Hubber dkk. (2006) juga mengemukakan bahwa lignoselulose dalam biomassa dapat menjadi sumber karbon yang potensial untuk produksi bahan bakar cair terbarukan dan bahan kimia. Sharma dkk (2015) mengemukkakan bahwa pirolisis adalah proses dekomposisi termokimia dimana biomassa dirubah menjadi padatan yang kaya karbon dan volatile matter tanpa adanya oksigen. Hasil pirolisis biomassa berupa arang (char), biooil, dan gas. Tujuan penelitian ini adalah mengetahui pengaruh suhu serta mengetahui parameter kinetika dari pirolisis enceng gondok.

\section{Metode Penelitian}

Bahan baku yang digunakan pada penelitian ini adalah enceng gondok yang diperoleh dari Waduk Cengklik Boyolali, Jawa Tengah. Biomassa tersebut dikeringkan terlebih dahulu dengan pemanasan sinar matahari dan selanjutnya dipotong $10 \mathrm{~cm}$, serta ditimbang sesuai kebutuhan untuk percobaan pirolisis.

Tabel 1. Komposisi yang terkandung dalam enceng gondok

\begin{tabular}{|c|c|}
\hline Komposisi lignoselulosa & \\
\hline - $\quad$ Hemiselulosa \% & 35,9807 \\
\hline - $\quad$ Selulosa \% & 14,9092 \\
\hline - $\quad$ Lignin $\%$ & 16,2248 \\
\hline - $\quad$ Lain-lain & 32,8853 \\
\hline \multicolumn{2}{|l|}{ Analisis Proximat } \\
\hline - $\quad$ Kadar air, $\%$ & 19,0588 \\
\hline - Volatile matter, $\%$ & 53,5377 \\
\hline - $\quad$ Kadar abu, \% & 13,4600 \\
\hline $\begin{array}{l}\text { - Kadar karbon terikat, } \\
\%\end{array}$ & 41,8303 \\
\hline - Nilai kalor, cal/gr & 2986,3211 \\
\hline \multicolumn{2}{|l|}{ Analisa Ultimat } \\
\hline - $\quad \mathrm{C} \%$ & 33,91 \\
\hline - $\quad \mathrm{H} \%$ & 6,09 \\
\hline - $\mathrm{O} \%$ & 42,86 \\
\hline - $\quad \mathrm{N} \%$ & 1,2 \\
\hline - $\quad \mathrm{S} \%$ & 0,15 \\
\hline
\end{tabular}

Enceng godok yang dipakai hanyalah bagian batang dan daun saja. Komposisi enceng gondok dapat dilihat pada Tabel 1

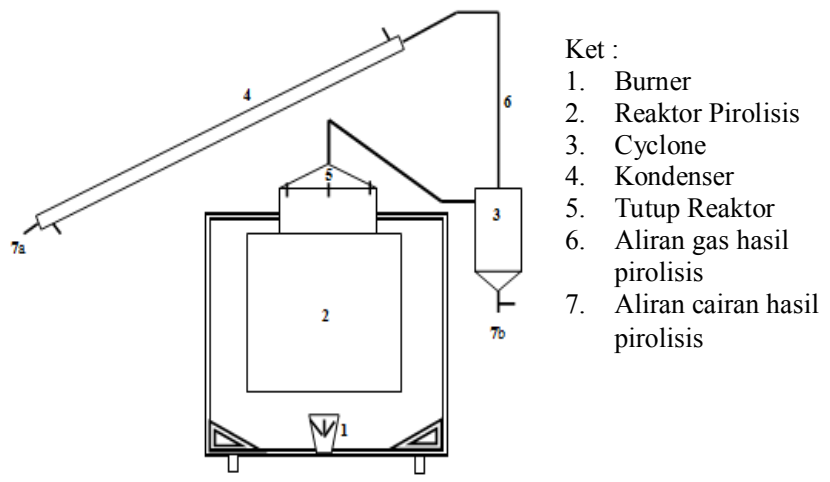

Gambar 1. Rangkaian Alat Pirolisis

Rangkaian alat yang digunakan pada proses pirolisis ditunjukkan pada Gambar 1. Proses pirolisis yang dilakukan pada penelitian ini adalah metode slow pirolisis.

Konfigurasi alat terdiri dari reaktor dengan diameter 25 $\mathrm{cm}$, tinggi $47 \mathrm{~cm}$ yang dilengkapi dengan cyclone berdiameter $15 \mathrm{~cm}$ dan tinggi $30 \mathrm{~cm}$ untuk memisahkan hasil gas dan padatan.

\section{Model Kinetika}

Menurut Sun dkk (2011) pirolisis biomassa dianggap reaksi orde satu. Thurner dan Mann (1981) mempresentasikan pirolisis biomassa menggunakan Compatting model. Mekanisme reaksinya dapat dihat pada Gambar 2.

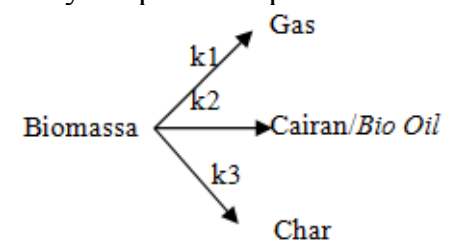

Gambar 2. Mekanisme reaksi pirolisis

Dari mekanisme reaksi di atas dapat diturunkan ke dalam persamaan neraca massa sebagai berikut:

Neraca massa Enceng gondok $\left(\mathrm{m}_{\mathrm{B}}\right)$

$\frac{d m_{B}}{d t}=-\left(k_{o v}\right) m_{B}$

Neraca massa gas $\left(\mathrm{m}_{\mathrm{G}}\right)$

$\frac{d m_{G}}{d t}=k_{1} m_{B}$

Neraca massa cairan/bio-oil

$\frac{d m_{T}}{d t}=k_{2} m_{B}$

Neraca massa Char

$\frac{d m_{C}}{d t}=k_{3} m_{C}$ 
Kondisi mula-mula untuk persamaan 2 sampai 4 adalah :

$$
\begin{aligned}
& \text { Pada } t=0 ; \quad m_{B t=0}=m_{B 0} ; \quad m_{G t=0}=0 ; m_{T t=0}=0 ; \\
& m_{C t=0}=0 ;
\end{aligned}
$$

Dalam hal ini $t$ dalam menit dan $m$ dalam gram.Proses pirolisis yang dipelajari merupakan proses non-isotermal sehingga terjadi kenaikan suhu dari kondisi lingkungan sampai waktu tak hingga. Untuk mempelajari fenomena kenaikan suhu ini dapat didekati dengan persamaan (5), yaitu saat kenaikan suhu dari awal hingga suhu tercapai dan saat suhu telah tercapai .

$$
\frac{d T}{d t}=a T^{b}
$$

Persamaan Arrhenius digunakan untuk menghitung konstanta kecepatan reaksi pada persamaan 1 sampai dengan 4, yakni dengan menggunakan persamaan 6 .

$$
k=A \exp \left(-\frac{E}{R T}\right)
$$

Pada saat $\mathrm{T}=\mathrm{T}_{0}$

$$
k_{0}=A \exp \left(-\frac{E}{R T_{0}}\right)
$$

dengan satuan $\mathrm{T}$ dalam ${ }^{\circ} \mathrm{C}$ dan $\mathrm{k}$ dalam menit ${ }^{-1}$.

Dengan menentukan nilai parameter kinetika $\mathrm{k}_{1 \mathrm{o}}, \mathrm{k}_{2 \mathrm{o}}$, $\mathrm{k}_{3 \mathrm{o}}$, dan energi aktivasi $\mathrm{E}_{1}, \mathrm{E}_{2}, \mathrm{E}_{3}(\mathrm{~J} / \mathrm{mol})$ maka persamaan Arrhenius dapat menjadi

$$
\begin{aligned}
& k_{1}=k_{1_{0}} \exp \left[-\frac{E_{1}}{R}\left(\frac{1}{T}-\frac{1}{T_{0}}\right)\right] \\
& k_{2}=k_{2_{0}} \exp \left[-\frac{E_{2}}{R}\left(\frac{1}{T}-\frac{1}{T_{0}}\right)\right] \\
& k_{3}=k_{3_{0}} \exp \left[-\frac{E_{3}}{R}\left(\frac{1}{T}-\frac{1}{T_{0}}\right)\right]
\end{aligned}
$$

Setelah nilai parameter kinetika $\mathrm{k}_{10}, \mathrm{k}_{20}, \mathrm{k}_{30}$ didapat dikembalikan untuk menghitung nilai faktor tumbukan (A menit $^{-1}$ ) menggunakan persamaan 11 .

$$
A=k_{0} \exp \left(\frac{E}{R T_{0}}\right)
$$

Dari hasil penelitian akan diperoleh data massa gas, massa cairan tiap waktu dan massa char pada waktu dan suhu tertentu. Kemudian data tersebut diubah menjadi fraksi massa dengan membagi massa tiap produk dengan massa biomassa awal. Setelah dimasukkan ke persamaan yang ada diselesaikan secara numeris. Untuk memperoleh nilai $\mathrm{k}_{1 \mathrm{o}}, \mathrm{k}_{2 \mathrm{o}}, \mathrm{k}_{30}, \mathrm{E}_{1}, \mathrm{E}_{2}, \mathrm{E}_{3}, \mathrm{a}, \mathrm{b}$. Nilai $R$ square $\left(R^{2}\right)$ sebagai selisih antara massa produk pirolisis dari data eksperimen dengan massa produk pirolisis terhitung (simulasi) dan nilai $\mathrm{k}$ diperoleh pada nilai $R^{2}$ yang paling mendekati 1. Persamaan 12 digunakan untuk mencari nilai
$\mathrm{R}^{2}$. Nilai parameter kinetika $\left(\mathrm{k}_{0}\right)$ dan nilai energi aktivasi (E) dapat gunakan untuk mengitung $\mathrm{k}$ dari model yang diusulkan.

$$
R^{2}=1-\frac{\text { SSres }}{\text { SStot }}
$$

\section{Hasil dan Pembahasan}

\subsection{Pengaruh suhu dan perolehan yield}

Produk yang diperoleh dari proses pirolisis adalah padatan (bio-char), cair (bio-oil) dan gas. Gas yang dihasilkan dari proses pirolisis selanjutnya dikondensasikan melalui kondenser sehingga diperoleh tar berwujud cair. Sedangkan non-condensable gas akan tetap diperoleh dalam wujud gas. Diantara produk yang dihasilkan pada proses pirolisis, bio-oil merupakan produk utama yang diinginkan.

Menurut Kittiphop dkk (2012) proses pirolisis untuk memproduksi bio-oil dilakukan pada suhu $450-600^{\circ} \mathrm{C}$. Shafizadeh dan Chin (1977) mengatakan bahwa pembentukan char, bio-oil dan gas merupakan hasil dekomposisi dari selulosa, hemiselulosa dan lignin. Hemiselulose yang merupakan komponen paling stabil terurai pada 498-598 K, selulosa pada 598-648 K dan pada suhu 523-773 K untuk lignin.

Hasil percobaan pengaruh suhu dan perolehan yield dapat dilihat pada Gambar 3. Dari hasil percobaan yang telah dilakukan, banyaknya bio oil yang terbentuk terjadi pada suhu $600^{\circ} \mathrm{C}$ yaitu sebesar $46,2 \%$. Sedangkan pada suhu operasi 400,500 dan $700^{\circ} \mathrm{C}$ yield bio-oil yang diperoleh tidak terlalu signifikan. Pada suhu $700^{\circ} \mathrm{C}$ terbentuk bio-oil yang hampir sama jumlahnya pada saat suhu $500^{\circ} \mathrm{C}$, akan tetapi dalam mencapai suhu $700^{\circ} \mathrm{C}$ energi yang dibutuhkan untuk mencapai kondisi ini sangat besar sehingga penggunaan suhu tersebut tidak efisien. Hasil padatan (char) menunjukkan semakin tinggi suhu mengalami penurunan. Dan hasil gas semakin tinggi suhu mengalami kenaikan hal ini dikarenakan terjadi penguapan senyawa organik dan dekomposisi hemiselulosa, selulosa dan lignin. Dari hasil percobaan tersebut diperoleh suhu optimal untuk menghasilkan bio-oil paling banyak adalah pada suhu $600^{\circ} \mathrm{C}$. Sedangkan untuk suhu operasi diatas $600^{\circ} \mathrm{C}$, yield produk yang paling banyak adalah gas. Pada suhu yang tinggi biomassa akan cenderung terkonversi menjadi gas noncondensable dibandingkan produk bio-oil. Distribusi produk pirolisis pada penelitian ini tersaji pada Tabel 2.

Tabel 2. Hasil analisis pirolisis.

\begin{tabular}{cccc}
\hline $\mathrm{T},{ }^{\circ} \mathrm{C}$ & $\begin{array}{c}\text { Massa Bio } \\
\text { oil, gr }\end{array}$ & Massa Gas, gr & Massa Char, gr \\
\hline 400 & 177 & 121 & 202 \\
500 & 160 & 165 & 175 \\
600 & 231 & 105 & 164 \\
700 & 164 & 203 & 133 \\
\hline
\end{tabular}




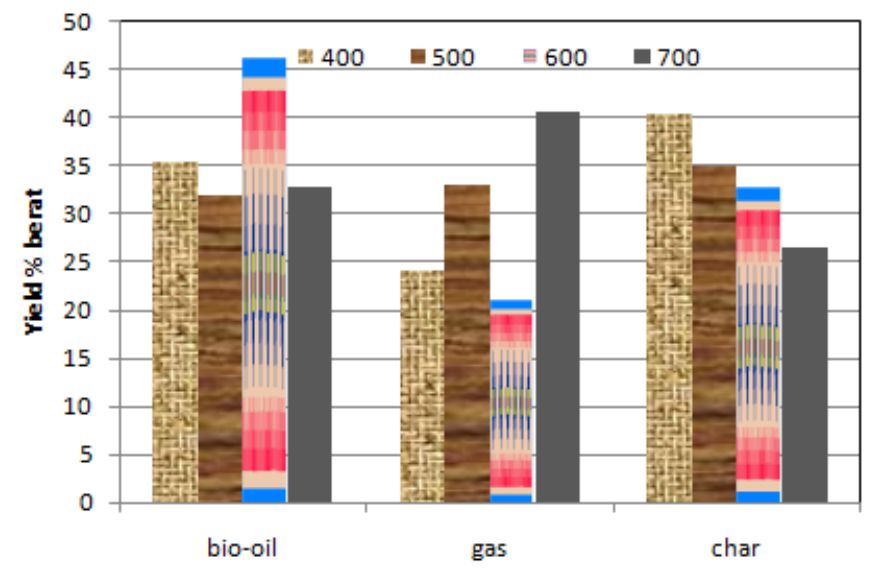

Gambar 3. Yield produk pirolisis

\subsection{Kinetika Reaksi}

Model kinetika Compatting Model adalah model yang dipilih untuk mempresentasikan fenomena yang terjadi pada pirolisis enceng gondok. Energi aktivasi pada penelitian ini diperlukan untuk memecah ikatan yang ada pada enceng gondok agar menghasilkan gas, bio-oil dan char. Energi aktivasi merupakan energi minimum yang harus dimiliki oleh molekul-molekul reaktan agar menghasilkan reaksi jika saling bertumbukan.

Sebagai catatan, parameter kinetika pembentukan gas, bio-oil dan gas yaitu nilai $k_{1_{0}}, k_{2_{0}}, k_{3_{0}}, E_{1}, E_{2}, E_{3}$ dihitung menggunakan program matlab dan untuk mendapatkan nilai parameter $\mathrm{A}_{1}, \mathrm{~A}_{2}$ dan $\mathrm{A}_{3}$ digunakan rumus pada persamaan (11). Nilai konstanta kecepatan reaksi pirolisis enceng gondok tersaji pada Tabel 3. Dari Tabel tersebut dapat dilihat pula bahwa energi aktivasi untuk pembentukan gas lebih besar dari pada energi aktivasi untuk pembentukan produk lain.

Tabel 3. Konstanta kecepatan reaksi pirolisis enceng gondok

\begin{tabular}{lc}
\hline $\mathrm{k}_{1 \mathrm{o}} \mathrm{men}^{-1}$ & 3,49 \\
\hline $\mathrm{k}_{2 \mathrm{o}} \operatorname{men}^{-1}$ & 0,34 \\
$\mathrm{k}_{3 \mathrm{o}} \operatorname{men}^{-1}$ & 0,25 \\
$\mathrm{E}_{1}(\mathrm{~J} / \mathrm{mol})$ & 14069,21 \\
$\mathrm{E}_{2}(\mathrm{~J} / \mathrm{mol})$ & 3059,45 \\
$\mathrm{E}_{3}(\mathrm{~J} / \mathrm{mol})$ & 2313,39 \\
\hline
\end{tabular}

\section{Kesimpulan}

Suhu optimum pirolisis enceng gondok untuk mengahasilkan bio-oil adalah pada suhu $600^{\circ} \mathrm{C}$. Konstanta kinetika reaksi untuk pirolisis enceng gondok pada pembentukan gas adalah $\mathrm{k}_{1}=3,4997 \mathrm{exp}^{-14069,21 / \mathrm{RT}} \mathrm{men}^{-1}$, konstanta kinetika reaksi pembentukan bio-oil adalah $\mathrm{k}_{2}=0,3430 \mathrm{exp}^{-3059,451 / R T} \mathrm{men}^{-1}$ dan konstanta kinetika reaksi pembentukan char adalah $\mathrm{k}_{3}=0,2526 \exp ^{-2313,395 / \mathrm{RT}^{-}} \mathrm{men}^{-1}$.

\section{Daftar Pustaka}

Bhattacharya, A. and Kumar, P., 2010, Water Hyacinth as a Potential Biofuel Crop, EJEAF Che, 9 (1), 112-122.

Gunawan, P. Dan Sahwalita, 2007, Pengolahan Enceng Gondok sebagai Bahan Baku Kertas Seni, Prosiding Ekspose Hasil-hasil Penelitian, Padang.

Huang, Y. H., Chiueh, P.T., Kuan, W. H., and Lo, S. L., 2013, Pyrolysis kinetics of biomass from product information, Appl Energ, 110, 1-8.

Hubber, G.W., Iborra, S., and Corma, A., 2006, Synthesis of Transportation Fuels from Biomass: Chemistry, Catalysts, and Engineering. Chem Rev. 106, 4044-4098.

Kittiphop, P., 2012, Physicochemical of Bio-Oil from Three Residual Plants Produced by Continous Pyrolysis Reactor, Int J Chem React Eng, 3, 2.

Shafizadeh, F. and Chin, P. P. S., 1977, Thermal deterioration of wood, ACS Symp. Ser., 57-81.

Sharma, A., Pareek, V., \& Zhang, D., 2015, Biomass pyrolysis- A review of modeling, process parameter and catalitytic studies, Renew Sust Energ Rev, 50, 10811096.

Shoeb, F. and Singh, H.J., 2002, Kinetic Studies of Biogas Eolved from Water Hyacinth, $2^{\text {nd }}$, Symp Enviro Agro, pp 138.

Sun, L., Chen, J.Y., Negulescu, I.I., Moore, M.A., and Collier, B.J., 2011.Kinetics modeling of dynamic pyrolysis of bagasse fibers, Bioresource Technol, 102 (2), 1951-1958.

Thurner, F. and Mann, U., 1981, Kinetic Investigation of Wood Pyrolysis. Ind Eng Chem Fund, 20: 482-488 